\title{
COMMUNICATION
}

\section{Multipodal dynamic coordination involving cation- $\pi$ interactions to control the structure of helical polymers}

Received 00th January 20xx, Mohammad Alzubi, ${ }^{\ddagger}$ Sandra Arias, ${ }^{\ddagger}$ Iria Louzao, Emilio Quiñoá, Ricardo Riguera * and Félix Freire*

Accepted 00th January 20xx

DOI: $10.1039 / x 0 x \times 00000 x$

www.rsc.org/

A precise tuning of the four possible states of a helix $(P / M$ helical sense and stretched/compressed helical backbone) is attained by controlling the complexation between $\mathrm{Li}^{+}$and a poly(phenylacetylene) that bears amide, ester and phenyl ring functionalities at the pendant group. Depending on the $\mathrm{MeOH}$ ratio that is present as cosolvent, different coordination sites are involved leading to complexes I-III, each one with a characteristic structure (tri-, bi-, unipodal) and associated helical state. This dynamic coordination allows the selective modification of the helical sense or the stretching/compression backbone of a helical polymer.

The control of the helical sense and elongation of helical polymers, ${ }^{1}$ by the action of external stimuli, ${ }^{1-4}$ has attracted the attention of the scientific community due to the potential interest of those materials in applications as sensors, ${ }^{2}$ molecular devices, ${ }^{3}$ chiro-optical switches, ${ }^{4}$ memory elements and chiral catalysts. ${ }^{5}$ Poly(phenylacetylene)s ${ }^{6}$ are a family of helical polymers especially suited for those applications due the wide range of substituents available and above all, their dynamic behaviour that allows a helical PPA to invert or amplify its helical sense, and even to modulate its elongation by the action of an external stimuli. ${ }^{7}$

In our group we recently described that a poly(phenylacetylene) bearing the anilide of the (R)- $\alpha$ methoxy- $\alpha$-phenylacetic acid as pendant [poly- $(R)-1$ ], (null $C D$, axially racemic due to the $1: 1 \mathrm{sp} / \mathrm{ap}$ conformational ratio), ${ }^{8}$ can be specifically shifted to adopt either the $P$ or the $M$ helical sense by addition - in $\mathrm{CHCl}_{3}$ solution - of a small amount of a monovalent metal ion $\left(\mathrm{Na}^{+}\right.$or $\left.\mathrm{Ag}^{+}\right)$that, depending on the amount of a crucial donor cosolvent (i.e., $\mathrm{MeOH}$ ), chelates the

\footnotetext{
${ }^{a}$ Centro Singular de Investigación en Química Biolóxica e Materiais Moleculares(CIQUS) and Departamento de Química Orgánica, Universidade de Santiago de Compostela, E-15782 Santiago de Compostela, Spain.

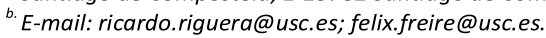

c. Electronic Supplementary Information (ESI) available: Structures, synthesis and spectral data of monomers and homopolymers; CD, UV, GPC, DSC, NMR and IR studies for PPA/Li+ complexes. See DOl:10.1039/x0xx00000x

${ }^{d .} \neq$ These authors contributed equally
}

pendant in two different ways, each one promoting one helical sense in the backbone. ${ }^{9}$ From the structural point of view, this change in complexation/helical sense involves the control of the formation and cleavage of a cation- $\pi$ interaction.

Herein, we describe a more sophisticated system where tuning the complexation of the metal ion with different groups in the pendants allows not only the control on the helical sense of the polymer but also on the elongation of the chain.

To this end, we devised a pendant comprising three complexation sites with different coordinating ability and located at adequate distance for chelation: two carbonyl groups and an aromatic ring for metal cation $-\pi$ interaction).

This pendant should be able to complex the metal ion in different ways, generating complexes whose different structures and interactions with the vicinal pendants will determine a given helix for each one (Scheme 1).

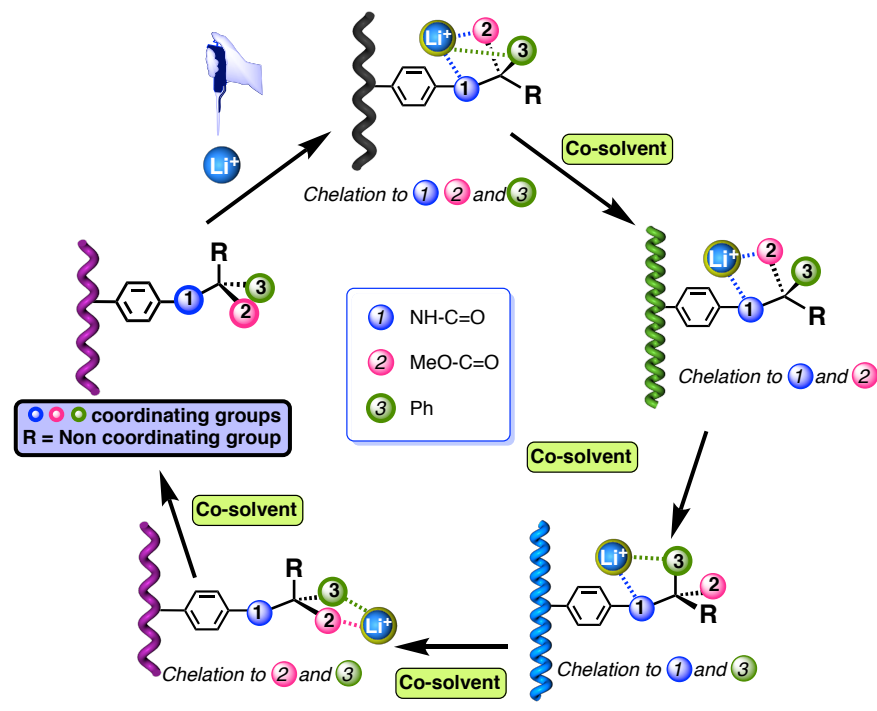

Scheme 1. Potential structural changes (sense, elongation) in a helical polymermetal complex due to the presence of different chelation modes.

In this paper, we demonstrate this successful idea using as pendants the benzamides of $(S)$-phenylglycine methyl ester [m$(S)-2],{ }^{10}$ and (S)-phenylalanine methyl ester [m-(S)-3], where their amide, ester and phenyl ring functions act as complexing 
sites (Figure 1). We will show also that selective conversion of the PPA into its complexes allows the preparation of the four different helical states, represented by the $P$ and $M$ helical senses and compressed/stretched skeleton.

Thus, 4-ethynylbenzamide of L-phenylglycine methyl ester and $L$-phenylalanine methyl ester were prepared and polymerized using $\left[\{\mathrm{Rh}(\mathrm{nbd}) \mathrm{Cl}\}_{2}\right]$ as catalyst (nbd= 2,5-norbornadiene) that gave the poly-(S)-2 and poly-(S)-3 PPAs in good yield (90\% and 93\% respectively) and with a high content of the cis configuration of the double bonds (see SI for details).

$C D$ studies of poly-(S)-2 and poly-(S)-3 in chloroform (0.3 $\mathrm{mg} / \mathrm{mL}$ ) show a preferred helical structure -helix Iassociated to the presence of a preponderant anticonformation (the two carbonyls oppositely oriented in the pendant group, Figure 2). ${ }^{10}$ a)

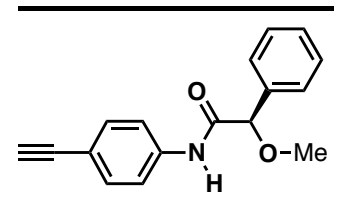

$\mathrm{m}-(R)-1$

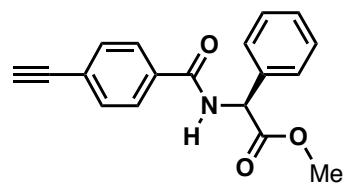

$\mathrm{m}-(S)-2$

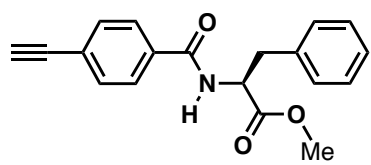

$\mathrm{m}-(S)-3$

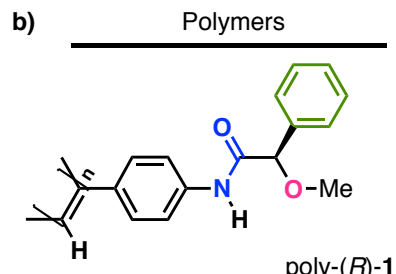

poly- $(R)-1$
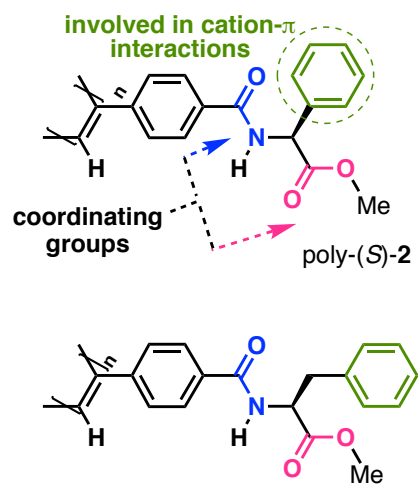

poly-(S)-3
Figure 1. a) Structure of monomers $m-(S)-1, m-(S)-2, m-(S)-3$ and functional groups potentially involved in interaction with $\mathrm{LiClO}_{4}$.

Next, lithium perchlorate in $\mathrm{MeOH}(10 \mathrm{mg} / \mathrm{mL})$ was added to a chloroform solution of poly-(S)-(2 or 3) $(0.3 \mathrm{mg} / \mathrm{mL})$ to prepare poly-(S)-2/Li ${ }^{+} / \mathrm{MeOH}$ in a $1.0 / 0.5 / 133$ mole ratio and poly-(S)$3 / \mathrm{Li}^{+} / \mathrm{MeOH}$ in a $1.0 / 0.5 / 130$ mole ratio. ${ }^{11}$ In these conditions [i.e., poly-(S)-(2 or 3$\left.) / \mathrm{Li}^{+} / \mathrm{MeOH}=1.0 / 0.5 /<135\right]$, complex $\mathrm{I}-$ where the metal ion coordinates both carbonyl groups (amide and ester) as inferred from IR studies - is formed (Figure 2). Moreover, ${ }^{7} \mathrm{Li} \mathrm{NMR}$ studies show a strong shielding of the ${ }^{7} \mathrm{Li}$ peak once poly-(S)-2 is present in the solution, resonating at $5.89 \mathrm{ppm}$, typical for a cation- $\pi$ interaction ${ }^{12}$ (similar results were obtained for the $\mathrm{Li} \mathrm{NMR}$ of poly-3/ $\mathrm{Li}^{+}$complex I). This chemical shift also indicates that $\mathrm{Li}^{+}$ion interacts with a single phenyl ring. ${ }^{13}$ Thus, in complex $\mathrm{I}$, the $\mathrm{Li}^{+}$ion chelate the two carbonyls in a syn orientation, establishing also an extra cation$\pi$ interaction with the aryl ring of the amino acid (Figure $2 b$ ). During the formation of this complex, a helical inversion is observed from helix I to helix II, due to the conformational change produced at the pendant moiety, which places the bulkiest group in the opposite direction.

Next, complex I was titrated with different amounts of $\mathrm{MeOH}$ to study the dynamic coordination chemistry of the poly-(S)-(2 or 3$) / \mathrm{Li}^{+}$system.
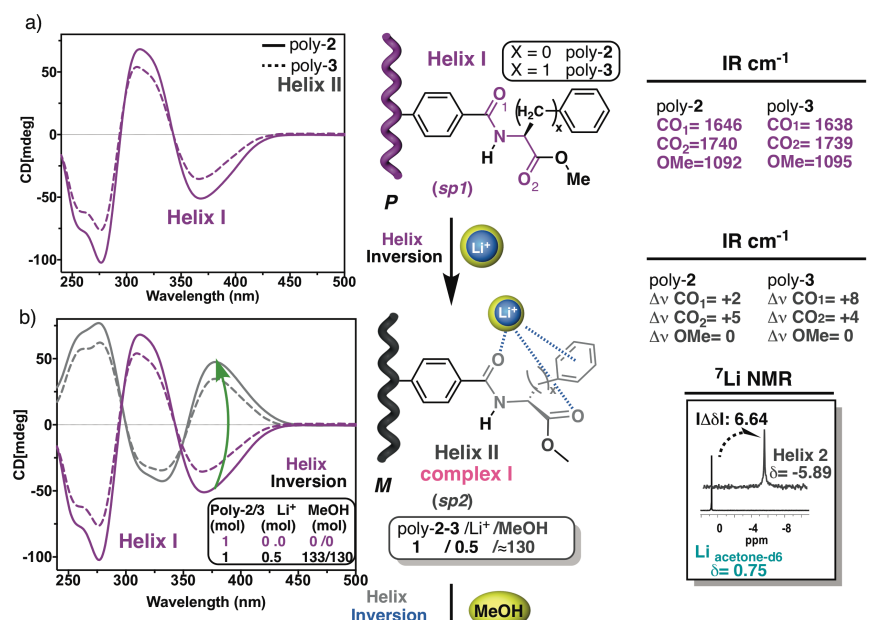
$\Delta v \mathrm{O}_{2}=+5 \quad \Delta v \mathrm{CO}_{2}=+4$
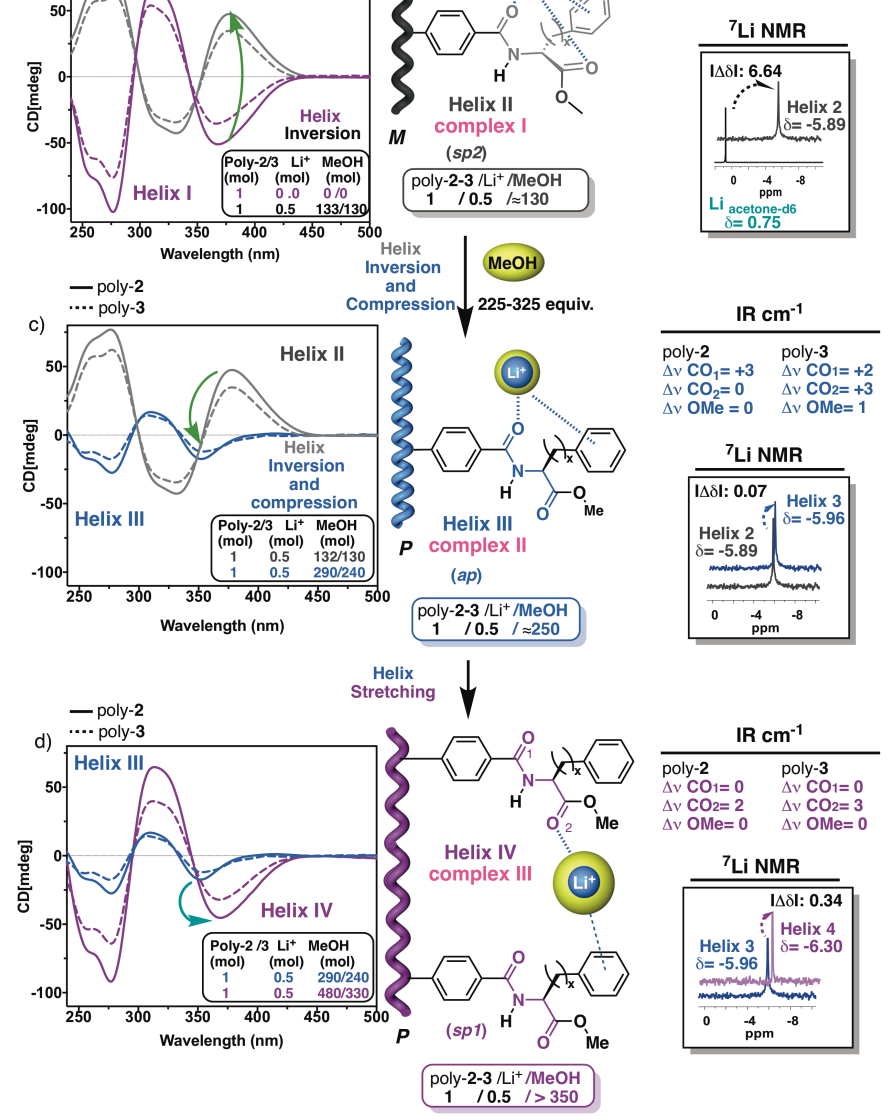

Figure 2. (a) $\mathrm{CD}$ spectra of poly-(S)-2 and poly-(S)-3 in $\mathrm{CHCl}_{3}$, showing the same anti-conformation at the pendant group (helix I). CD, IR and Li NMR studies demonstrating the dynamic coordination chemistry of a poly-(S) -(2 or $3) / \mathrm{Li}^{+} / \mathrm{MeOH}$ complex in a (b) $1.0 / 0.5 / \approx 130$ ratio (helix II), (c) $1.0 / 0.5 / \approx 250$ ratio (helix III) and (d) 1.0/0.5/>350 ratio (helix IV).

Interestingly, it was found that when the amount of $\mathrm{MeOH}$ added to the poly-(S)-(2 or $\mathbf{3}) / \mathrm{Li}^{+}$complex is in a poly-(S)-2 
(mru)/MeOH ratio of $1 /(278-326)(\mathrm{mol} / \mathrm{mol})$, and in a poly-(S)$3(\mathrm{mru}) / \mathrm{MeOH}$ ratio of $1 /(226-277)(\mathrm{mol} / \mathrm{mol})$, a new helical inversion was produced associated to the evolution of complex I to a new complex II (Figure 2c). In complex II, the metal ion remains coordinated to the amide group -inferred from IR studies-, and to the $\pi$ system - determined by ${ }^{7} \mathrm{Li} \mathrm{NMR}$ analysis: $\delta\left({ }^{7} \mathrm{Li}\right)=-5.96 \mathrm{ppm}$ for poly-2/Li ${ }^{+}$and $-6.04 \mathrm{ppm}$ for poly-3/ $\mathrm{Li}^{+}{ }^{13}$ but the linkage with the ester group has disappeared (Figure 2). Thus, in complex II the metal ion has only two points for chelation and the complex adopts the anticonformation producing a helical structure with the same helical sense as helix I. In fact, this second inversion clearly shows a hypsochromic shift observed both at the CD and UV spectra (Figure 2 and $\mathrm{SI}$ ). Thus, complex II is structurally represented by a helix with the same sense as helix I, but a more compressed scaffold (Figure 2 and $\mathrm{SI}$ ).

Finally, the addition of a larger amount of methanol - poly-(S)(2) $/ \mathrm{Li}^{+} / \mathrm{MeOH}$ in a $1.0 / 0.5 />380(\mathrm{~mol} / \mathrm{mol} / \mathrm{mol})$ ratio, and poly(S)-(3) $/ \mathrm{Li}^{+} / \mathrm{MeOH}$ in a $1.0 / 0.5 />330(\mathrm{~mol} / \mathrm{mol} / \mathrm{mol})$ ratio-, produced another structural change in the complex formed between the $\mathrm{Li}^{+}$ion and the pendant group. In this new mode of complexation (i.e., complex III), the metal ion "jumps" from the amide to the ester group, without altering the anti conformation at the pendant moiety, and therefore no helical inversion is observed (Figure 2d). On the other hand, examination of the CD and UV spectra indicate the stretching of the helix once complex III is formed (see Figure $2 \mathrm{~d}$ and $\mathrm{SI}$ for details). This elongation is explained by the presence of a cation- $\pi$ interaction $\left[\delta\left({ }^{7} \mathrm{Li}\right) \approx-6.2 \mathrm{ppm}\right.$ for poly- $(2$ or 3$\left.) / \mathrm{Li}^{+}\right]$ between vicinal amino acid groups (Figure $2 d$ ). In this way, the anti conformation will remain unaltered, while the constraint originated by the placement of the metal ions between neighbouring pendants is released via elongation of the polyene chain.

In order to demonstrate the generality of this sequential modification of a helix and the role of the different groups, we perform the same studies using a different PPA. In this case, we chose poly-(S)-4, bearing the benzamide of L-alanine methyl ester as pendant group that differs from the previously studied ones in the replacement of the $\mathrm{Ph}$ ring found in poly-(S)-2 by a methyl group (Figure 3).

$\mathrm{CD}$ spectra of poly- $(\mathrm{S})-\mathbf{4}$ in $\mathrm{CHCl}_{3}(0.3 \mathrm{mg} / \mathrm{mL})$ shows a practically identical $C D$ trace to the one adopted by poly-(S)-(23) (Figure 3a) indicating that the three polymers adopt the same helical structure (helix 1 ).

Addition of $\mathrm{LiClO}_{4}$ in $\mathrm{MeOH}(10 \mathrm{mg} / \mathrm{mL})$ to the chloroform solution of poly- $(S)-4(0.3 \mathrm{mg} / \mathrm{mL})$ where poly- $(S)-4 / \mathrm{Li}^{+}$is in a $1.0 / 0.5(\mathrm{~mol} / \mathrm{mol})$ ratio, produced a helical inversion with formation of a complex I, in a similar manner as that observed for poly-(S)-(2 or 3) $/ \mathrm{Li}^{+} / \mathrm{MeOH}$ in a $1.0 / 0.5 /<135(\mathrm{~mol} / \mathrm{mol} / \mathrm{mol})$ ratio (Figure 2 ). In this case, the helix inversion observed in complex-I of poly-(S)-4 is due to the adoption of a syn conformation at the pendant group, induced by the chelation of the two carbonyl groups with the monovalent metal ion and without cation- $\pi$ interaction (Figure 3 ).

Ulterior additions of $\mathrm{MeOH}$ produce the inversion of the helical sense directly forming helix IV (Figure 3). Contrary to what was observed in poly-(S)-(2 or 3), the presence of helix III was not detected. This is related to the absence in poly-(S)-4, of the cation $-\pi$ bonding, necessary to stabilize the complex leading to helix III (see complex II in Figure 2). Moreover, ${ }^{7} \mathrm{Li}$ NMR $\left[\delta\left({ }^{7} \mathrm{Li}\right) \approx\right.$ $-2 \mathrm{ppm}$ ] confirmed the absence of any cation $-\pi$ interaction in all the poly-(4)/Li+ complexes.

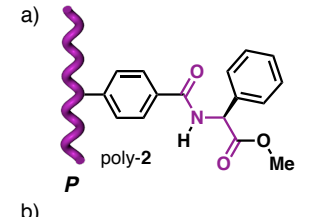

b)
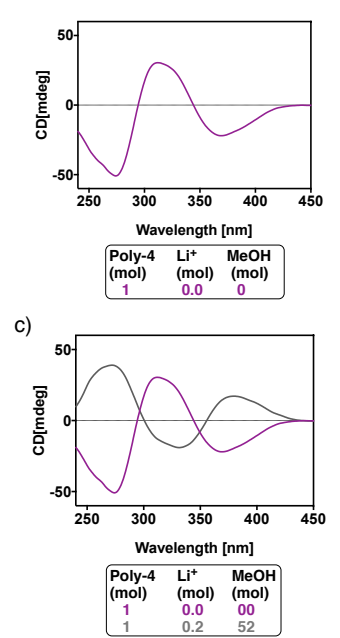

d)

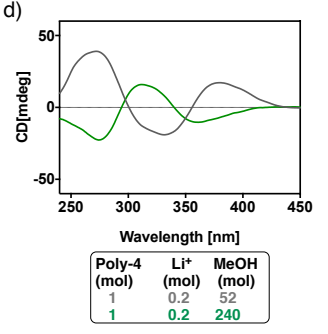

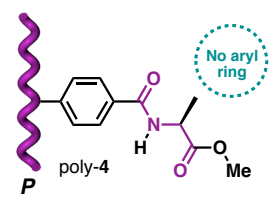
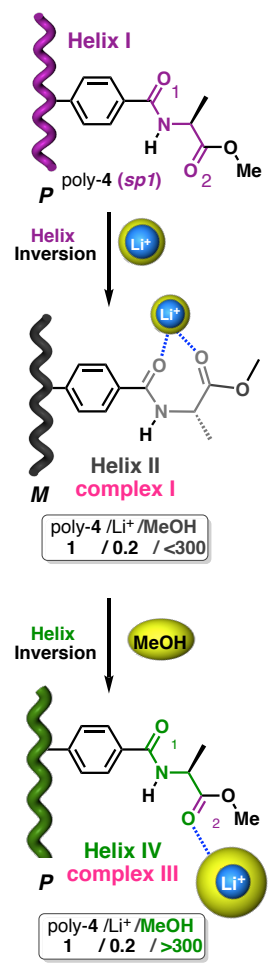

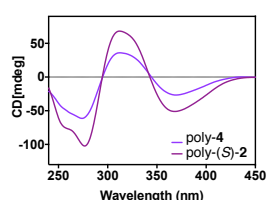

IR

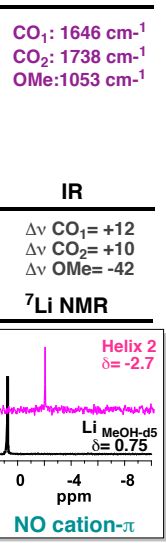

IR

$\Delta v \mathrm{CO}_{1}:+4 \mathrm{~cm}^{-1}$ $\Delta v \mathrm{CO}_{2}:+6 \mathrm{~cm}^{-1}$ $\triangle v$ OMe: $-46 \mathrm{~cm}^{-1}$

${ }^{7} \mathrm{Li} \mathrm{NMR}$

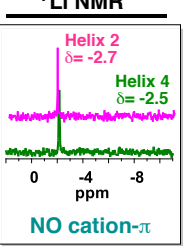

Figure 3. (a) $C D$ spectra of poly-(S)-2 and poly-(S)-4 showing the anticonformation at the pendant group (helix I). CD, IR and Li-NMR studies demonstrating the dynamic coordination chemistry of a poly-(S)-(4)/Li+/MeOH complex in (b) a $1.0 / 0.0 / 0$ ratio (helix I), (c) a $1.0 / 0.5 / 132$ ratio (helix II) and (d) a
$1.0 / 0.5 / 240$ ratio (helix III).

In conclusion, it has been demonstrated that addition of low amounts of $\mathrm{Li}^{+}$salt to a polyphenylacetylene with pendants containing amide, ester and phenyl ring functions at precise distances, allows the sequential formation of three different complexes (complexes I-III) each one involving different coordination sites (amide, ester and cation- $\pi$ ) and structures (tri-, bi-, unipodal) that modify the helical sense or the stretching/compression of the original helix. The dynamic character of the complexation allows its manipulation by controlled addition of $\mathrm{MeOH}$ that debilitates some coordinations and favours others.

In this way, a single helical polymer can be forced to adopt any of the four forms of a helix $(P / M$ sense and stretched/compressed backbone) by selection of the complexing state (uncomplexed polymer and complexes I-III). 
We think that this approach can be extended to other dynamic helical polymers, where adequate selection of the pendant groups and metal ion could generate multiple helical structures via dynamic coordination chemistry.

We thank Ministerio de Economía y Competitividad [CTQ201570519-P, CTQ2014-61470-EXP], Erasmus Mundus (M. Alzubi), Fundación Gil Dávila (S. Arias), Xunta de Galicia (Centro singular de investigación de Galicia accreditation 2016-2019, GRC2014/040) and European Union (European Regional Development Fund - ERDF) for financial support.

\section{Notes and references}

1 (a) E. Yashima, K. Maeda and Y. Furusho, Acc. Chem. Res., 2008, 41, 1166; (b) E. Yashima, K. Maeda, H. lida, Y. Furusho and K. Nagai, Chem. Rev., 2009, 109, 6102; (c) J. Liu, J. W. Y. Lam and B. Z. Tang, Chem. Rev., 2009, 109, 5799; (d) B. M. Rosen, C. J. Wilson, D. A. Wilson, M. Peterca, M. R. Imam and V. Percec, Chem. Rev., 2009, 109, 6275; (e) E. Schwartz, M. Koepf, H. J. Kitto, R. J. M. Nolte and A. E. Rowan, Polym. Chem, 2011, 2, 33

2 (a) E. Anger, H. lida, T. Yamaguchi, K. Hayashi, D. Kumano, D. Crassous, N. Vanthuyne, C. Rousselc and E. Yashima, Polym. Chem., 2014, 5, 4909; (b) H. lida, M. Miki, S. Iwahana and E. Yashima, Chem. Eur. J. 2014, 20, 4257; (c) S. Leiras, F. Freire, J. M. Seco, E. Quiñoá and R. Riguera, Chem. Sci., 2013, 4, 2735.

3 (a) P. Thodupunuri, S. Katukuri, K. V. Ramakrishna, G. Sharma, A. C. Kunwar, A. Sarma and H. Hofmann. J. Org. Chem., 2017, 82, 2018; (a) B. L. Feringa, Acc. Chem. Res., 2001, 34, 504.

4 (a) S. Sakurai, K. Okoshi, J. Kumaki and E. Yashima, J. Am. Chem. Soc., 2006, 128, 5650; (b) K. Okoshi, S. Sakurai, J. K. Ohsawa and E. Yashima, Angew. Chem., Int. Ed., 2006, 45, 8173; (c) D. Pijper, M. G. M. Jongejan, A. Meetsma and B. L. Feringa, J. Am. Chem.Soc., 2008, 130, 4541.

5 (a) M. Burgess, J. S. Moore and J. R. López, Acc. Chem. Res., 2016, 49, 2649; (b) X. Liu, L. Lin and X. Feng, Acc. Chem. Res., 2011, 44, 574; (c) H. lida and E. Yashima, Synthesis and Application of Helical Polymers with Macromolecular Helicity Memory, in Polymeric Chiral Catalyst Design and Chiral Polymer Synthesis, ed. Itsuno, S., John Wiley \& Sons, Hoboken, NJ, USA, 2011, ch. 7, p 201.
6 (a) F. Freire, E. Quiñoá and R. Riguera, Chem. Rev., 2016, 116, 1242; (b) E. Yashima, N. Ousaka, D. Taura, K. Shimomura, T. Ikai and K. Maeda, Chem. Rev., 2016, 116, 13752; (c) J. G. Rudick, V. Percec, Acc. Chem. Res., 2008, 41, 1641; (d) E. Yashima and K. Maeda, Macromolecules, 2008, 41, 3; (e) E. Yashima and K. Maeda, Helically Folding Polymers in Foldamers: Structure Properties and Applications; Eds: S. Hecht, I. Huc, WILEY- VCH, Weiheim, 2007, pp 331; (f) K. Maeda and E. Yashima, Top. Curr. Chem., 2006, 265, 47; (g) H. Nakako, R. Nomura, M. Tabata and T. Masuda, Macromolecules, 1999, 32, 2861.

7 (a) S. Arias, M. Núñez-Martínez, E. Quiñoá, R. Riguera and F. Freire, Small, 2017, 13, 1602398; (b) S. Arias, F. Freire, E. Quiñoá and R. Riguera, Angew. Chem. Int. Ed., 2014, 53, 13720; (c) F. Freire, J. M. Seco, E. Quiñoá and R. Riguera, J. Am. Chem. Soc., 2012, 134, 19374; (d) J. Bergueiro, F. Freire, E. P. Wendler, J. M. Seco, E. Quiñoá and R. Riguera, Chem. Sci., 2014, 5, 2170.

8 (a) R. Rodríguez, J. Ignés-Mullol, F. Sagués, E. Quiñoá, R. Riguera and F. Freire, Nanoscale, 2016, 8, 3362; (b) F. Freire, J. M. Seco, E. Quiñoá and R. Riguera, Angew. Chem. Int. Ed., 2011, 50, 11692

9 (a) S. Arias, J. Bergueiro, F. Freire, E. Quiñoá and R. Riguera, Small. 2016, 12, 238; (b) S. Arias, F. Freire, E. Quiñoá and R. Riguera, Polym. Chem, 2015, 6, 4725.

10 I. Louzao, J. M. Seco, E. Quiñoá and R. Riguera, Angew. Chem., Int. Ed., 2010, 49, 1430

11 The use of $\mathrm{MeOH}$ is necessary to dissolve the lithium perchlorate salt, but at this point the amount added can be considered negligible to affect the poly (S)-(2-3)/ $\mathrm{Li}^{+}$complex. As far as other metal ions is concerned, $\mathrm{Na}^{+}$gave no inversion and $\mathrm{Ag}^{+}$gave just helices II and IV, with less $\mathrm{MeOH}$ needed to cause the changes.

12 (a) L. Liu, T. Namikoshi, Y. Zang, T. Aoki, S. Hadano, Y. Abe, I. Wasuzu, T. Tsutsuba, M. Teraguchi and T. Kaneko, J. Am. Chem. Soc., 2013, 135, 602; (b) T. Aoki, T. Kaneko, N. Maruyama, A. Sumi, M. Takahashi, T. Sato and M. Teraguchi, J. Am. Chem. Soc., 2003, 125, 6346; (c) M. Tabata, Y. Tanaka, Y. Sadahiro, T. Sone, Yokota and K. I. Miura, Macromolecules, 1997, 30, 5200; (d) C. I. Simionescu, V. Percec and S. Dumitrescu, J. Polym. Sci. Polym. Chem. Ed., 1977, 15, 2497.

13 (a) V. Ya Lee, R. Kato, M. Ichinhe and A. Sekiguchi, J. Am. Chem. Soc., 2005, 127, 13142; (b) J. W. Caldwell and P. A. Kollman, J. Am. Chem. Soc., 1995, 117, 4177; (c) A. Sekiguchi, Y. Sugai, K. Ebata, C. Kabuto and H. Sakurai, J. Am. Chem. Soc., 1993, 115, 1144; (d) R. A. Kumpf and D. A. Dougherty, Science, 1993, 261, 1708. 


\section{COMMUNICATION}

TOC

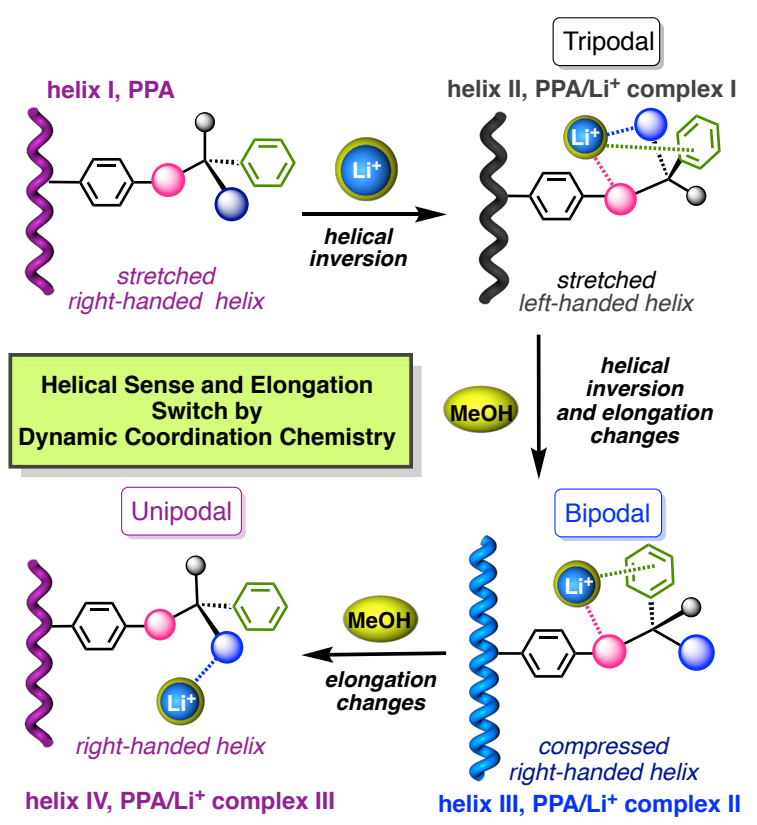

Dynamic coordination, by means of multipodal metal complexes and cation- $\pi$ interactions, controls the structure of helical polymers 